\title{
DEXAMETHASONE, METOCLOPRAMIDE, AND THEIR COMBINATION FOR THE PREVENTION OF POSTOPERATIVE NAUSEA AND VOMITING IN FEMALE PATIENTS WITH MODERATE-TO-HIGH RISK FOR PONV UNDERGOING LAPAROSCOPIC SURGERY
}

\author{
Aidah Alkaissi' ${ }^{1}$ Mohammad Dwaikat ${ }^{2}$, Nouraldin Almasri ${ }^{3}$ \\ ${ }^{1}$ Assistant Professor, Department of Anaesthesiology and Intensive Care, Faculty of Medicine and Health Sciences, Nursing and \\ Midwifery Department, An-Najah National University, Nablus, Palestine. \\ ${ }_{2}^{2}$ MSN Anaesthesia Nurse, Faculty of Graduate Studies, An-Najah National University, Nablus, Palestine. \\ ${ }_{3}^{3}$ MD Anaesthesiologist and Intensive Care, Rafidia Hospital, Palestinian Ministry of Health, Palestine
}

ABSTRACT

\section{BACKGROUND}

There is evidence that in patients with a high risk of developing Postoperative Nausea and Vomiting (PONV), combination of antiemetics is considered. The aim is to evaluate the effect of prophylactic dexamethasone and metoclopramide as monotherapy and in combination for female patients with moderate-to-high risk for PONV undergoing laparoscopic surgery under general anaesthesia.

\section{MATERIALS AND METHODS}

This was a multicentred, prospective, randomised, double-blind, placebo controlled trial. 120 patients, were allocated randomly to one of the four groups: (D) received $8 \mathrm{mg}$ dexamethasone; (M) received $20 \mathrm{mg}$ Metoclopramide; (C) received dexamethasone (8 $\mathrm{mg}$ ) and metoclopramide (20 mg); and (P) received saline. All patients were assessed 24 hours for PONV, postoperative symptoms and the need for rescue antiemetic and analgesia.

\section{RESULTS}

In the 24-hour post-operative period, the following results were demonstrated; Significant differences in the incidence of vomiting between placebo group 17 patients (56.7\%) and combination group $6(20 \%), \mathrm{P}=0.0037$, and dexamethasone group $6(20 \%), \mathrm{P}=$ 0.0037. The results indicate that incidence of overall vomiting was reduced by use of either Dexamethasone or combination. Also statistically significant differences were noted in the incidence of nausea between the treatment groups [D 6 (20\%); M 10 (33.3\%); and C 5 (16.7\%)] when compared with placebo 19 (63.3\%), p< 0.05. The results indicate that the three treatments groups have similar effect in reducing overall incidence of nausea. Significant differences were also exhibited in the intensity of nausea between the combination group $1.05( \pm 0.90)$ compared with dexamethasone $1.78( \pm 1.14), \mathrm{P}=0.008$, Metoclopramide $2.43( \pm 1.03), \mathrm{P}=$ 0.000 and placebo $3.07( \pm 1.34), P=0.000$. Results demonstrate that using a combination can significantly reduce the intensity of nausea. The total number of patients who received rescue antiemetic in combination 6 (20\%) and dexamethasone 7 (23.3\%) were significantly lower than those receiving placebo 19 (63.3\%), p <0.05. Incidence, intensity of pain and the consumption of rescue analgesic were reduced significantly in the combination and dexamethasone groups compared with Metoclopramide and Placebo.

\section{CONCLUSION}

The combination of dexamethasone plus metoclopramide reduces the intensity of nausea. Dexamethasone and a Dexamethasone plus Metoclopramide was found more effective in preventing PONV and decreasing the requirement of rescue antiemetic than Metoclopramide or placebo. Patients who are at high risk for PONV may demonstrate positive outcomes when using a combination therapy.

\section{KEYWORDS}

Postoperative Nausea and Vomiting, Dexamethasone, Metoclopramide.

HOW TO CITE THIS ARTICLE: Alkaissi A, Dwaikat M, Almasri N. Dexamethasone, metoclopramide, and their combination for the prevention of postoperative nausea and vomiting in female patients with moderate-to-high risk for PONV undergoing laparoscopic surgery. J. Evolution Med. Dent. Sci. 2017;6(75):5353-5359, DOI: 10.14260/Jemds/2017/1162

\section{BACKGROUND}

There is evidence that in patients with a high risk for PONV, combination antiemetic should be considered as a viable option.[1] It has been reported that dexamethasone is effective

Financial or Other, Competing Interest: None.

Submission 18-07-2017, Peer Review 05-09-2017,

Acceptance 12-09-2017, Published 00-09-2017.

Corresponding Author:

Dr. Aidah Alkaissi,

Faculty of Medicine and Health Sciences,

Nursing and Midwifery Department,

An-Najah National University,

P.O. Box 7, Nablus, Palestine.

E-mail: aidah@najah.edu

DOI: $10.14260 /$ jemds $/ 2017 / 1162$ against emesis in most patients undergoing General Anaesthesia (GA).[2] Dexamethasone and a Dexamethasone plus Metoclopramide combination was found more effective in preventing PONV than Metoclopramide alone or no antiemetic administration.[3]

In addition, Manaa and Seif found that the combination of Dexamethasone with Metoclopramide was not significantly more effective than single administration of Dexamethasone in the prophylaxis of PONV in patients undergoing maxillofacial surgery. ${ }^{[4]}$ The aim of this study is to evaluate the effect of prophylactic dexamethasone and metoclopramide as monotherapy and in combination for female patients with moderate-to-high risk for PONV undergoing laparoscopic surgery under general anaesthesia. 


\section{MATERIALS AND METHODS}

This was a multicentred, prospective, randomised, doubleblind, placebo controlled trial. The study was conducted in the Northern West Bank, Palestine.

\section{Inclusion Criteria}

Female patients with

(1) Age between 18-60 years, (2) weight between $50-120 \mathrm{~kg}$,

(3) who were planned for laparoscopic surgery under GA, (4) American Society of Anesthesiologists (ASA) I \& II, (5) who were with a risk score of $\geq 60 \%$ for PONV.[5]

\section{Exclusion Criteria}

(1) History of gastrointestinal haemorrhage, (2) smokers, (3) developed nausea and vomiting on the last day on prior surgery, (4) received antiemetic drugs within 24 hours on prior surgery, (5) conversion to open cholecystectomy.

The main outcome was the occurrence of PONV. A secondary outcome was the intensity of nausea, assessed by a self-report Likert type scale[6] ranging from 0 to $6(0=$ no nausea, $1=$ very mild nausea, $2=$ mild, $3=$ moderate, $4=$ severe, $5=$ very severe, $6=$ intolerable). Indication for treating nausea and vomiting was when the patient felt nausea $\geq 3$ on a Likert type scale and/or when the patient vomited twice or more. Then a single dose of an antiemetic drug for the rescue, Ondansetron $4 \mathrm{mg}$ given. Other outcomes included the incidence and intensity of pain, measured with a VAS score ${ }^{[7]}$ spans from $0-10(0=$ no pain and $10=$ the worst pain that may be possible) measured at postoperative hours immediately after surgery in PACU, 2, 4, 8, 16, 24 hours. A score of 4 and above on VAS-scale was defined as pain requiring of an analgesic drug (2 $\mathrm{mg}$ of IV of Morphine) repeated as needed. Complete response (no nausea, no vomiting, no retching, no need for rescue antiemetic) is another outcome. Patient's satisfaction was measured by a scale of statements including very unsatisfied, unsatisfied, neither satisfied nor unsatisfied, satisfied, and very satisfied.

\section{Assignment of Interventions}

Study drugs were processed by a nurse unrelated to the study. Medication was administered in a $10 \mathrm{~mL}$ syringe. Syringes were labelled with a study-specific identification i.e. a number for each patient. The anaesthetist administered the study medication and was unaware of the distribution of the treatment groups.

\section{Sample Size Calculation}

A formula (i.e. Pocock's sample size formula) that can be directly applied for comparison of proportions $\mathrm{P}_{1}$ and $\mathrm{P}_{2}$ in two equally sized groups where $\mathrm{P}_{1}=$ estimated proportion of study outcome in the exposed group (i.e. combination therapy) $\left(\mathrm{P}_{1}=0.30\right)$ and $\mathrm{P}_{2}=$ estimated proportion of study outcome in the unexposed group (placebo therapy) (P2 = 0.60 ). Thus, a total of 160 patients ( 40 for each group) should be targeted for recruitment into the study, at an alpha level of 0.05 and a power of (1-beta) of 0.80 . Due to limited time for this study, a total of 120 patients (30 for each group) were recruited.

\section{Randomisation}

Randomisation was done through opaque and well-sealed envelopes. The sequence generation was done by computer.
Number was written on envelope and group was written on the card within it along with the serial number. As and when patients come, envelop was opened to see the group to be allotted.

\section{Blindness}

The patients, health care providers included in the patient care, the person who collected and analysed data, and the outcome adjudicators were unaware of the treatment group allocation.

\section{Administration of Study Medications}

One hundred twenty participants were allocated randomly to one of the four study groups, 30 in each group. Study medications were given by anaesthetists.

Group one received $8 \mathrm{mg}$ Dexamethasone one minute before induction of anaesthesia and $10 \mathrm{~mL}$ saline before termination of anaesthesia (D).

Group Two received $10 \mathrm{~mL}$ saline one minute before administration of anaesthesia and Metoclopramide $20 \mathrm{mg}$ before termination of anaesthesia (M).

Group Three received Dexamethasone (8 $\mathrm{mg}$ ) one minute before administration of anaesthesia and Metoclopramide (20 mg) before termination of anaesthesia (C).

Group Four received $10 \mathrm{~mL}$ saline one minute before administration of anaesthesia and before termination of anaesthesia (P).

\section{Anaesthesia Protocol}

Fifteen minutes before the administration of anaesthesia, the participants were pre-medicated with Dormicum $1 \mathrm{mg}$ IV. Lactated Ringer at a rate of $10 \mathrm{~mL} / \mathrm{kg}$ was administered to all participants. Monitoring throughout anaesthesia period done by electrocardiogram, noninvasive blood pressure, pulse oximetry and capnometry. The same consistent anaesthetic approach was used in all participants. GA was induced with Fentanyl $(2 \mu \mathrm{g} / \mathrm{kg})$ and Propofol $(2 \mathrm{mg} / \mathrm{kg})$. Atracurium was given $(0.5 \mathrm{mg} / \mathrm{kg})$ for ease of tracheal intubation. Anaesthesia contained $1.2 \%$ Isoflurane, $50 \%$ air in $\mathrm{O}_{2}$. The ventilation was mechanically controlled and modified to preserve end-tidal of carbonic dioxide (ETCO2) between 35 and $40 \mathrm{mmHg}$. At the end of the operation, Atropine was administered $0.01 \mathrm{mg} / \mathrm{kg}$ and Neostigmine $0.05 \mathrm{mg} / \mathrm{kg}$ IV for repeal of muscle relaxation and the endotracheal tube was removed.

\section{Surgical Protocol}

Patients were put in reverse Trendelenburg position and the abdominal cavity was insufflated with $\mathrm{CO}_{2}$ till intraabdominal pressure between 13-15 mmHg was achieved. A temporal nasogastric tube was inserted to enhance gastric drainage. Before endotracheal extubation, the nasogastric tube was suctioned again and then pulled out.

\section{Data Collection}

Participants were relocated to the post-anaesthetic care unit (PACU). $\mathrm{O}_{2}$ saturation was monitored, while heart rate, blood pressure, and respiratory rate were monitored each $15 \mathrm{~min}$. Oxygen (5 L/min.) was administered via face mask on admission and stopped before transfer to the ward.

In the ward, the patients were evaluated at $2,4,8,16$, and 24 hours after surgery by a nurse unaware of which antiemetic the patient had received. 
Ondansetron $4 \mathrm{mg}$ IV was administered when the Likert type scale was 3 and above and/or when the frequency of vomiting was twice or more. The occurrence of nausea, vomiting and the number of patients requiring rescue antiemetic were recorded.

Intensity of pain assessed through VAS each 1 hour in PACU and at 4-hour periods in the ward. Morphine $2 \mathrm{mg}$ IV was given to the patient when pain score on VAS was 4 or above and when the patient requested analgesia. The occurrence of any side effects, headache, dizziness, tiredness and fatigue, during the study period was evaluated.

\section{Data Analysis}

The data was analysed using SPSS version 20. Means, standard deviations, percentages and frequencies were used to describe data for each group, Chi Square test was utilised to examine differences between Percentages, Tukey HSD Post-Hoc test examined pairwise differences between means, and One-Way Analysis of Variance (F-Test) was used to examine the differences between means.

\section{Ethical Consideration}

The study followed the World Medical Association Declaration of Helsinki Ethical Principles for Medical Research on Humans. ${ }^{[8]}$ Approval of the study was taken from the Institutional Review Board (IRB) at An-Najah National University.

\section{RESULTS}

\begin{tabular}{|c|c|c|c|c|c|c|}
\hline \multicolumn{2}{|c|}{ Variable } & $\begin{array}{c}\text { Dexamethasone } \\
\mathbf{n}=30\end{array}$ & $\begin{array}{c}\text { Metoclopramide } \\
\mathrm{n}=30\end{array}$ & $\begin{array}{c}\text { Combination } \\
n=30\end{array}$ & $\begin{array}{c}\text { Placebo } \\
\mathbf{n}=30\end{array}$ & P-value \\
\hline \multicolumn{2}{|c|}{ Age } & $37.43 \pm 10.28$ & $32.40 \pm 11.67$ & $36.20 \pm 13.17$ & $37.40 \pm 10.62$ & 0.284 \\
\hline \multirow{3}{*}{ BMI } & Normal & $5(16.7 \%)$ & $8(26.7 \%)$ & $7(23.3 \%)$ & $7(23.3 \%)$ & \multirow{3}{*}{0.732} \\
\hline & Overweight & $12(40 \%)$ & $8(26.7 \%)$ & $10(33.3 \%)$ & $9(30 \%)$ & \\
\hline & Obese & $13(43.3 \%)$ & $14(46.6 \%)$ & $13(43.3 \%)$ & $14(46.6 \%)$ & \\
\hline \multirow{4}{*}{ LMP (Days) } & $0-8$ & $8(26.7 \%)$ & $7(23.3 \%)$ & $12(40 \%)$ & $6(20 \%)$ & \multirow{4}{*}{0.149} \\
\hline & $9-16$ & $11(36.7 \%)$ & $10(33.3 \%)$ & $8(26.7 \%)$ & $8(26.7 \%)$ & \\
\hline & $17-28$ & $2(6.7 \%)$ & $10(33.3 \%)$ & $4(13.3 \%)$ & $7(23.3 \%)$ & \\
\hline & $>28$ & $9(30 \%)$ & $3(10 \%)$ & $6(20 \%)$ & $9(30 \%)$ & \\
\hline \multicolumn{2}{|c|}{ Duration of Anaesthesia (min.) } & $80.77 \pm 20.45$ & $77.98 \pm 25.95$ & $75.90 \pm 30.61$ & $77.73 \pm 20.59$ & 0.898 \\
\hline \multicolumn{2}{|c|}{ Duration of Surgery (min.) } & $61.10 \pm 18.77$ & $56.57 \pm 26.26$ & $55.10 \pm 28.79$ & $59.07 \pm 20.60$ & 0.775 \\
\hline \multicolumn{2}{|c|}{ Total dose of Fentanyl $(\mu \mathrm{g})$ : } & $162.33 \pm 68.25$ & $168.17 \pm 88.89$ & $144.33 \pm 62.54$ & $172.33 \pm 79.82$ & 0.496 \\
\hline \multicolumn{2}{|c|}{ Total dose of Propofol (mg): } & $170.32 \pm 26.78$ & $168.21 \pm 24.65$ & $165.28 \pm 19.23$ & $169.33 \pm 28.54$ & 0.877 \\
\hline \multicolumn{7}{|c|}{ aphic Data and Operational Information } \\
\hline
\end{tabular}

Data are Mean \pm SD with P-values derived from ANOVA test.

Data include Frequencies and Percentages (\%) with P-values derived from Chi Square test.

There were no statistically significant differences among the four groups according to Demographic data (Table 1).

\begin{tabular}{|c|c|c|c|c|c|}
\hline Variable & $\begin{array}{l}\text { Dexamethasone } \\
\mathbf{n}=\mathbf{3 0}\end{array}$ & $\begin{array}{l}\text { Metoclopramide } \\
\mathbf{n}=\mathbf{3 0}\end{array}$ & $\begin{array}{c}\text { Combination } \\
\mathbf{n}=\mathbf{3 0}\end{array}$ & $\begin{array}{c}\text { Placebo } \\
\mathbf{n}=30\end{array}$ & P-value \\
\hline Vomiting (In PACU) & $2(6.7 \%)$ & $7(23.3 \%)$ & $1(3.3 \%)$ & $14(46.7 \%)$ & $0.000^{*}$ \\
\hline Vomiting (In Ward) & $6(20 \%)$ & $8(26.7 \%)$ & $5(16.7 \%)$ & $14(46.7 \%)$ & $0.043^{*}$ \\
\hline Vomiting (In Total 24 hrs.) & $6(20 \%)$ & $10(33.3 \%)$ & $6(20 \%)$ & $17(56.7 \%)$ & $0.006^{*}$ \\
\hline Frequency of Vomiting (In PACU) & $1.5 \pm 0.71$ & $1.25 \pm 0.5$ & $1 \pm 0$ & $1.45 \pm 0.52$ & 0.788 \\
\hline Frequency of Vomiting (In Ward) & $1.67 \pm 0.52$ & $2.14 \pm 0.69$ & $1.8 \pm 0.84$ & $2.58 \pm 1.08$ & 0.162 \\
\hline Frequency of Vomiting (In Total 24 hrs.) & $1.58 \pm 0.49$ & $1.86 \pm 0.63$ & $1.67 \pm 0.82$ & $2.1 \pm 0.83$ & 0.439 \\
\hline Incidence of Nausea (In PACU) & $5(16.7 \%)$ & $9(30 \%)$ & $1(3.3 \%)$ & $19(63.3 \%)$ & $<0.001^{*}$ \\
\hline Incidence of Nausea (In Ward) & $6(20 \%)$ & $10(33.3 \%)$ & $5(16.7 \%)$ & $17(56.7 \%)$ & $0.008^{*}$ \\
\hline Incidence of Nausea (In Total 24 hrs.) & $6(20 \%)$ & $10(33.3 \%)$ & $5(16.7 \%)$ & $19(63.3 \%)$ & $<0.001^{*}$ \\
\hline Intensity of Nausea (In PACU) & $1.77 \pm 1.19$ & $2.33 \pm 1.35$ & $0.73 \pm 0.94$ & $3.17 \pm 1.60$ & $<0.01^{*}$ \\
\hline Intensity of Nausea (In Ward) & $1.80 \pm 1.32$ & $2.53 \pm 1.11$ & $1.37 \pm 1.19$ & $2.97 \pm 1.47$ & $<0.01^{*}$ \\
\hline Intensity of Nausea (In Total 24 hrs.) & $1.78 \pm 1.14$ & $2.43 \pm 1.03$ & $1.05 \pm 0.90$ & $3.07 \pm 1.34$ & $<0.01^{*}$ \\
\hline $\begin{array}{r}\text { Table } 2 . \text { The Inc } \\
\text { between }\end{array}$ & $\begin{array}{l}\text { of Postoperc } \\
\text { udy Groups i }\end{array}$ & $\begin{array}{l}\text { ausea, Vomit } \\
\text {, Ward and i }\end{array}$ & $\begin{array}{l}\text { tensity of } N c \\
\text { l } 24 \text { hours }\end{array}$ & & \\
\hline
\end{tabular}

*Significant at 0.05 level. Data are Mean \pm SD with Pvalues derived from ANOVA test.

Data include Frequencies and Percentages (\%) with Pvalues derived from Chi Square test.

In PACU, there were reported differences in the incidence of vomiting between groups of patients, $p=0.000$. The differences were in combination group 1 (3.3\%) and Dexamethasone group $2(6.7 \%)$ compared with placebo group 14 (46.7\%), $\mathrm{P}<0.05$, and in combination group 1
(3.3\%) compared with metoclopramide 7 (23.3\%), $\mathrm{P}=$ 0.0237. Results indicate that combination is more effective to reduce incidence of vomiting in PACU when compared with Metoclopramide or placebo (Table 2).

In the ward, the incidence of vomiting occurred in patients in the combination group 5 (16.7\%) and Dexamethasone group $6(20 \%)$ was significantly less than in the placebo group $14(46.7 \%), \mathrm{p}<0.05$. These results indicate 
that the effect of Metoclopramide is similar as to that of placebo (Table 2).

In 24 hours period after recovery, the incidence of vomiting in patients who received Dexamethasone alone 6 (20\%) or Dexamethasone plus Metoclopramide 6 (20\%) was significantly lower than those who had received placebo 14 (46.7\%), $p=0.0037$. The results suggest that the incidence of vomiting reduced significantly by use of either Dexamethasone as a monotherapy or in combination (Table 2).

In PACU, there were statistically significant differences reported in incidence of nausea between study groups, in Dexamethasone group 5 patients (16.7\%), Metoclopramide 9 (30\%), combination $1(3.3 \%)$ and placebo $19(63.3 \%)$, p $<0.001$. In order to identify where the statistical difference is located a Post Hoc test was used. The results indicated that there was a statistically significant difference between the three treatment groups when compared with placebo group $(\mathrm{p}<0.05)$. In addition, there was a significant difference between the combination group $1(3.3 \%)$ compared with the Metoclopramide $9(30 \%) \mathrm{p}=0.0059$. The author concluded that nausea could be reduced by using a combination, Dexamethasone or Metoclopramide; however, the combination effect was clearly superior over Metoclopramide (Table 2).

The number of patients who reported nausea while in the ward reduced significantly in the combination group 5 (16.7\%) and Dexamethasone group 6 (20\%) when compared with placebo group 17 (56.7\%), $\mathrm{p}<0.05$. Results reflect that Dexamethasone alone and in combination is more effective to reduce incidence of nausea than Metoclopramide and placebo group (Table 2).

During the postoperative period of 24 hours, there was significant difference between the treatment groups (D, M, and $\mathrm{C}$ ) when compared with placebo group $\mathrm{p}<0.05$. The results indicate that the three treatments groups (D, M, and C) have similar effect in reducing overall incidence of nausea (Table 2).

While in PACU, the intensity of nausea reduced significantly for the combination group (0.73) and Dexamethasone group (1.77) as compared with placebo (3.17), $p<0.05$. There are statistically significant differences between the combination group compared with Dexamethasone group $\mathrm{p}=0.013$, and Metoclopramide group at $p=0.000$. Results show that combination is more effective in reducing intensity of nausea of patients while in PACU as compared with Dexamethasone, Metoclopramide and placebo. However, it was noted that Combination treatment was superior to dexamethasone alone to reduce the intensity of nausea in PACU (Table 2).

In the ward, the intensity of nausea in the combination group (1.37) and Dexamethasone group (1.80) was significantly reduced when compared with the placebo group (2.97), at $\mathrm{p}<0.05$. There is a significant difference between the combination group as compared with Metoclopramide (2.53) at $p=0.003$. As a result, by using Dexamethasone or in combination the intensity of nausea was reduced in ward compared with the placebo group. In addition, combination therapy (1.37) was more effective than Metoclopramide (2.53), at $\mathrm{P}<0.01$ (Table 2).

Table 2 shows that during 24 hours postoperatively, the intensity of nausea in the combination group (1.05) was significantly less than in the Dexamethasone group (1.78), $\mathrm{P}=$ 0.008 . The cumulative score of nausea decreased in the Dexamethasone (1.78) and combination groups (1.05) as compared with a placebo group (3.07) at $p=0.000$ and the Metoclopramide group (2.43) at $\mathrm{p}=0.000$. However, it was noted that the combination therapy was superior to Dexamethasone alone, Metoclopramide alone and placebo. (Figure 1).

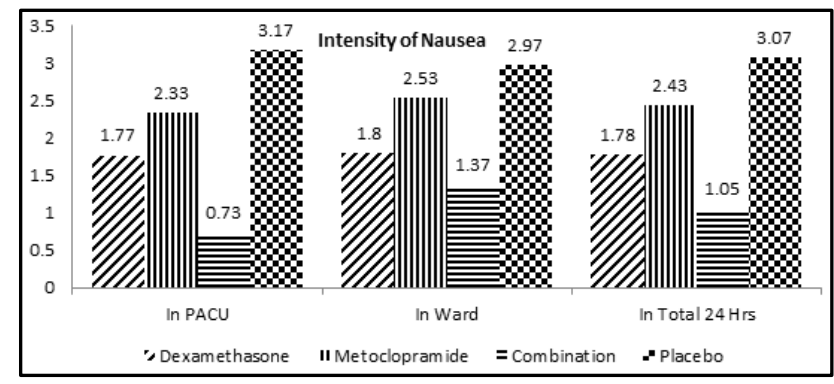

Figure 1. Intensity of Nausea in the Four Study Groups in PACU, Ward and in the Total 24 hours Post-operatively

\begin{tabular}{|c|c|c|c|c|c|}
\hline Variable & $\begin{array}{c}\text { Dexamethasone } \\
\mathbf{N = 3 0}\end{array}$ & $\begin{array}{c}\text { Metoclopramide } \\
\mathbf{N = 3 0}\end{array}$ & $\begin{array}{c}\text { Combination } \\
\mathbf{N = 3 0}\end{array}$ & $\begin{array}{c}\text { Placebo } \\
\mathbf{N = 3 0}\end{array}$ & $\begin{array}{c}\text { P-value } \\
\text { Headache }\end{array}$ \\
\hline Tiredness & $9(10 \%)$ & $9(30 \%)$ & $9(30 \%)$ & $8(26.7 \%)$ & 0.212 \\
\hline Drowsy & $10(33.3 \%)$ & $11(36.7 \%)$ & $7(23.3 \%)$ & $14(46.7 \%)$ & 0.265 \\
\hline Fatigue & $9(30 \%)$ & $14(46.7 \%)$ & $11(36.7 \%)$ & $13(43.3 \%)$ & 0.708 \\
\hline Incidence of Pain & $21(70 \%)$ & $12(40 \%)$ & $7(23.3 \%)$ & $11(36.7 \%)$ & 0.524 \\
\hline Intensity of Pain & $4.20 \pm 1.37$ & $28(93.3 \%)$ & $22(73.3 \%)$ & $29(96.7 \%)$ & $0.004^{*}$ \\
\hline
\end{tabular}

Table 3. The Numbers and Percentage of Patients with Postoperative Symptoms (Headache, Tiredness, Drowsy and Fatigue) in the Four Study Groups in the Total 24 hours Postoperatively. The Intensity of Pain is Presented by Mean \pm SD

*Significant at 0.05 level. Data are Mean \pm SD with P-values derived from ANOVA test.

Data include Frequencies and Percentages (\%) with P-values derived from Chi Square test.

There are no significant differences in postoperative symptoms (headache, tiredness, drowsy, and fatigue) between groups of patients in the total 24 hours postoperatively ( $p>0.05$ ) (Table 3). During the 24 hours, the results demonstrate that the incidence and intensity of pain decreased significantly by the use of Dexamethasone alone or in combination (Table 3). 


\begin{tabular}{|c|c|c|c|c|c|}
\hline Variable & $\begin{array}{c}\begin{array}{c}\text { Dexamethasone } \\
\mathrm{N}=30\end{array} \\
\end{array}$ & $\begin{array}{c}\text { Metoclopramide } \\
\mathrm{N}=\mathbf{3 0}\end{array}$ & $\begin{array}{c}\begin{array}{c}\text { Combination } \\
\mathrm{N}=30\end{array} \\
\end{array}$ & $\begin{array}{c}\begin{array}{c}\text { Placebo } \\
\mathrm{N}=30\end{array} \\
\end{array}$ & P-value \\
\hline Rescue Antiemetic (Ondansetron) & $7(23.3 \%)$ & $13(43.3 \%)$ & $6(20 \%)$ & $19(63.3 \%)$ & $0.000^{*}$ \\
\hline $\begin{array}{l}\text { Rescue Analgesic } \\
\text { (Morphine) }\end{array}$ & $21(70 \%)$ & $28(93.3 \%)$ & $22(73.3 \%)$ & $29(96.7 \%)$ & $0.004^{*}$ \\
\hline
\end{tabular}

Table 4. The Frequency and Percentage of Patients requiring Rescue Antiemetic and Rescue Analgesic Medications in the Four Study Groups in the Total 24 hours Postoperative Period

*Significant at 0.05 level. Data include Frequencies and Percentages (\%) with P-values derived from Chi Square test.

During the 24 hours, the results suggest that using Dexamethasone alone or in combination reduces the need for rescue antiemetic compared with placebo. However, it was noted that combination therapy was superior to metoclopramide alone and placebo to reduce the requirements for rescue antiemetic medication (Table 4). During the 24 hours, the consumption of rescue analgesic decreased significantly by the use of dexamethasone alone or in combination (Table 4).

\begin{tabular}{|c|c|c|c|c|c|}
\hline Variable & $\begin{array}{c}\text { Dexamethasone } \\
\mathrm{N}=\mathbf{3 0}\end{array}$ & $\begin{array}{c}\begin{array}{c}\text { Metoclopramide } \\
\mathrm{N}=30\end{array} \\
\end{array}$ & $\begin{array}{c}\text { Combination } \\
\mathrm{N}=\mathbf{3 0} \\
\end{array}$ & $\begin{array}{c}\text { Placebo } \\
\mathrm{N}=\mathbf{3 0} \\
\end{array}$ & P-value \\
\hline $\begin{array}{c}\text { Very } \\
\text { Unsatisfied }\end{array}$ & $2(6.7 \%)$ & 7 (23.3\%) & $0(0 \%)$ & $9(30 \%)$ & \multirow{5}{*}{$0.014^{*}$} \\
\hline Unsatisfied & $5(16.7 \%)$ & $4(13.3 \%)$ & $4(13.3 \%)$ & $7(23.3 \%)$ & \\
\hline Neither Satisfied nor Unsatisfied & $1(3.3 \%)$ & $0(0 \%)$ & $0(0 \%)$ & $0(0 \%)$ & \\
\hline Satisfied & $21(70 \%)$ & $17(56.7 \%)$ & $22(73.3 \%)$ & $13(43.3 \%)$ & \\
\hline $\begin{array}{c}\text { Very } \\
\text { Satisfied }\end{array}$ & $1(3.3 \%)$ & $2(6.7 \%)$ & $4(13.3 \%)$ & $1(3.3 \%)$ & \\
\hline
\end{tabular}

*Significant at 0.05 level. Data include Frequencies and Percentages (\%) with P-values derived from Chi Square test.

The results show that the patients who received prophylactic antiemetic were more satisfied with their health status as compared with those who received placebo. The highest rate of satisfaction was significantly noted in patients who received a combination therapy.

\begin{tabular}{|c|c|c|c|c|c|}
\hline Variable & $\begin{array}{c}\text { Dexamethasone } \\
\mathbf{N = 3 0}\end{array}$ & $\begin{array}{c}\text { Metoclopramide } \\
\mathbf{N = 3 0}\end{array}$ & $\begin{array}{c}\text { Combination } \\
\mathbf{N = 3 0}\end{array}$ & $\begin{array}{c}\text { Placebo } \\
\mathbf{N = 3 0}\end{array}$ & P-value \\
\hline Complete response & $23(76.6 \%)$ & $17(56.6 \%)$ & $24(80 \%)$ & $11(36.6 \%)$ & $0.001^{*}$ \\
\hline Incidence of PONV & $7(23 \%)$ & $13(43 \%)$ & $6(20 \%)$ & $19(63 \%)$ & $0.001^{*}$ \\
\hline
\end{tabular}

Table 6. In Total 24 hours Postoperatively, Frequency (\%) of Patients with Complete Response (No Nausea, No Retching, No Vomiting and No Need for Rescue Antiemetic Medication) and the Incidence of PONV in the Four Study Groups

*Significant at 0.05 level. Data include Frequencies and Percentages (\%) with P-values derived from Chi Square test. The results clarify that the number of patients with complete response in combination is significantly greater than metoclopramide and placebo. The overall incidence of PONV in dexamethasone, Metoclopramide, combination and placebo groups is $23 \%, 43 \%, 20 \%$, and $63 \%$ respectively in total 24 hours postoperatively (Table 6).

\section{DISCUSSION}

The overall incidence of PONV in the current study in the placebo group is $63.3 \%$, which is congruent with a study which revealed that the incidence of PONV ranges from $40 \%$ $77 \%$ for patients undergoing laparoscopic surgery.[9]

PONV is considered as the most widespread adverseeffect of perioperative opioids.[10] Premedication with opioids ${ }^{[11,12]}$ and intraoperative use raises the risk of PONV in a dose-dependent manner.[13] The Society for Ambulatory Anesthesia Consensus guidelines recommend reducing the use of opioid intraoperative and postoperative in a way to manage PONV.[14] Paradoxically, Andersen and Krohg noted that opioids did not increase the frequency of nausea, but actually relieved it.[15]

In the current study, more patients in the placebo group requested rescue analgesic (Morphine) suggestive of higher incidence of PONV. Our results are congruent with a previous study.[16]
The recommended dose for Metoclopramide is $10 \mathrm{mg}$ IV.[9] However, Metoclopramide is not effective in reducing PONV at a $10 \mathrm{mg}$ dosage.[1,17,18] Metoclopramide has identical efficiency compared with another antiemetic at the 25-50 mg dosage.[13] However, Gan et al in their guidelines don't encourage using Metoclopramide as a perioperative antiemetic.[14]

Because of its short duration of action, Metoclopramide must be given at the end of operation or after arrival to the PACU to produce an effective antiemetic in the early time postoperatively.[19] Henzi et al demonstrate that the antiemetic effect of Metoclopramide exists through the first six hours after administration. ${ }^{[18]}$ In the current trial, when 20 mg Metoclopramide was administered as a single prophylactic antiemetic at the end of anaesthesia, the relative risk reduction (RRR) was -0.316, the effects were comparative to a placebo in the total 24 hours postoperatively.

Dexamethasone has been found effective in preventing PONV in various randomised, placebo controlled studies in laparoscopic surgeries.[2,3,17,20-26] Henzi et al analysed 17 studies comparing the efficacy of prophylactic Dexamethasone with a placebo for PONV, and found it more effective than placebo.[27] Conversely, Fujii et al conducted a study in women undergoing major gynaecological operations, and found that Dexamethasone at $8 \mathrm{mg}$ dose alone did not reduce PONV.[28] 
The most frequent dose of Dexamethasone used for prevention of PONV is 8-10 mg (Aziz, Naz et al, 2011). In addition, advised timing for administration is instantly before administration of anaesthesia.[29] Therefore, for the current study, $8 \mathrm{mg}$ dexamethasone was given one minute before induction and the RRR of PONV in 24 hours is -0.632 compared with placebo.

Use of prophylaxis combination therapy against PONV has shown to have superior efficiency than monotherapy and should be adopted in patients at high risk score for PONV.[30] For the current study, combination of $8 \mathrm{mg}$ dexamethasone and $20 \mathrm{mg}$ Metoclopramide was given and the RRR of PONV in 24 hours is -0.684 when compared with placebo.

Use of Metoclopramide in combination with other agents has not been found to decrease the incidence of PONV more than monotherapy.[31] However, Jee et al reported that a combination of $20 \mathrm{mg}$ Metoclopramide with $5 \mathrm{mg}$ dose of Dexamethasone had similar effect against PONV as a combination of $4 \mathrm{mg}$ Ondansetron with $5 \mathrm{mg}$ Dexamethasone in patients undergoing gynaecological operation. ${ }^{[30]}$

However, a meta-analysis conducted by Henzi et al, informed that $10 \mathrm{mg}$ Metoclopramide has a poor antiemetic effect and its efficacy didn't improve when administered with 8 mg Dexamethasone.[18] In the current trial, a Dexamethasone plus Metoclopramide combination was found to be at least as effective as Dexamethasone alone for the preventing of PONV. The current findings are identical to those reported by Nesek-Adam et al, the results demonstrated no variance in the occurrence of PONV during the study period (24 hours) between the groups who received Dexamethasone alone and combination.[22] The current results also are congruent to the study of Ivanov et al. They found that the administration of Dexamethasone alone or in combination with Metoclopramide was more efficient in reducing PONV compared with Metoclopramide alone or without an antiemetic.[3]

The most prevalent side effects reported in the current study were headache, tiredness, fatigue, drowsiness. However, the difference was not statistically significant between the groups. These results are consistent with that of Ivanov et al who reported that in spite of the neuroleptic characteristics of Metoclopramide, its combination with Dexamethasone didn't increase incidence of headache, dizziness, sedation, or dry mouth. ${ }^{[3]}$

Coloma \& Duffy reported that a single dosage of Dexamethasone minimised postoperative pain scores. ${ }^{[32]}$ Due to its anti-inflammatory characteristic, Dexamethasone should be useful for acute pain after surgery.[33] Moreover, when using a single dose of Dexamethasone, the side effects are benign, as reported in various studies and metaanalysis.[33-35] This result is consistent with the findings of the current study.

In the current study, rescue antiemetic in 24 hours was significantly lower in the dexamethasone and combination groups than the other groups. On the contrary, Ivanov et al found that rescue antiemetic was not required in patients receiving Dexamethasone and combination, after laparoscopic surgery.[3].[29]

In the current study, Dexamethasone reduced postoperative pain and analgesic requirements as compared with Metoclopramide or placebo. Similar results were obtained by Fukami et al who found that Dexamethasone significantly reduced postoperative pain and analgesic requirements after LC compared with the placebo group.[24]

\section{CONCLUSION}

The combination of dexamethasone plus metoclopramide reduces the intensity of nausea. Dexamethasone and Dexamethasone plus Metoclopramide was found more effective in preventing PONV and decreasing the requirement of rescue antiemetic than Metoclopramide or placebo. Patients who are at high risk for PONV may demonstrate positive outcomes when using a combination therapy.

\section{REFERENCES}

[1] McCracken G, Houston P, Lefebvre G, et al. Guideline for the management of postoperative nausea and vomiting. J Obstet Gynaecol Can 2008;30(7):600-7, 608-16.

[2] Khalaj AR, Miri SR, Porlashkari M, et al. Prophylactic anti-emetic effect of dexamethasone and metoclopramide on the nausea and vomiting induced by laparoscopic cholecystectomy: a randomized, double blind, placebo-controlled trial. J Minim Invasive Surg Sci 2013;2(1):18-22.

[3] Ivanov $\mathrm{K}$, Ignatov $\mathrm{V}$, Kolev $\mathrm{N}$, et al. Investigating the postoperative nausea and vomiting in patients after laparoscopic surgery - prophylaxis and feasibility. TJS 2008;6(4):29-32.

[4] Manaa EM, Seif SA. Postoperative nausea and vomiting management in maxillofacial procedures: Dexamethasone combined with metoclopramide. Eg J Anaesth 2012;28(2):163-8.

[5] Apfel CC, Laara E, Koivuranta M, et al. A simplified risk score for predicting postoperative nausea and vomiting: conclusions from cross-validations between two centers. Anesthesiology 1999;91(3):693-700.

[6] Morrow GR. Methodology in behavioral and psychosocial cancer research. The assessment of nausea and vomiting. Past problems, current issues and suggestions for future research. Cancer 1984;53(Suppl 10):2267-80.

[7] McCormack HM, Horne DJ, Sheather S. Clinical applications of visual analogue scales: a critical review. Psychol Med 1988;18(4):1007-19.

[8] World Medical Association. World Medical Association Declaration of Helsinki: ethical principles for medical research involving human subjects. JAMA 2013;310(20):2191-4.

[9] Habib AS, Gan TJ. Combination therapy for postoperative nausea and vomiting - a more effective prophylaxis? Ambul Surg 2001;9(2):59-71.

[10] Toner CC, Broomhead CJ, Littlejohn IH, et al. Prediction of postoperative nausea and vomiting using a logistic regression model. Br J Anaesth 1996;76(3):347-51.

[11] Bryson EO, Frost EA, Rosenblatt M. Management of the patient at high risk for postoperative nausea and vomiting. Middle East J Anaesthesiol 2007;19(1):1535.

[12] Lerman J. Surgical and patient factors involved in postoperative nausea and vomiting. $\mathrm{Br} \mathrm{J}$ Anaesth 1992;69(7 Suppl 1):24S-32S. 
[13] Pierre S, Whelan R. Nausea and vomiting after surgery. Continuing Education in Anaesthesia, Critical Care \& Pain 2013;13(1):28-32.

[14] Gan TJ, Diemunsch P, Habib AS, et al. Consensus guidelines for the management of postoperative nausea and vomiting. Anesth Analg 2014;118(1):85113.

[15] Andersen R, Krohg K. Pain as a major cause of postoperative nausea. Can Anaesth Soc J 1976;23(4):366-9.

[16] Langevin S, Lessard MR, Trepanier CA, et al. Alfentanil causes less postoperative nausea and vomiting than equipotent doses of fentanyl or sufentanil in outpatients. Anesthesiology 1999;91(6):1666-73.

[17] Aziz N, Naz U, Ilyas M. A comparative study between metoclopramide and dexamethasone for prevention of post-operative nausea and vomiting in laparoscopic cholecystectomy. J Med Sci 2011;19(3):129-32.

[18] Henzi I, Walder B, Tramer MR. Metoclopramide in the prevention of postoperative nausea and vomiting: a quantitative systematic review of randomized, placebo-controlled studies. $\mathrm{Br} \mathrm{J}$ Anaesth 1999;83(5):761-71.

[19] Watcha MF, White PF. Postoperative nausea and vomiting. Its etiology, treatment and prevention. Anesthesiology 1992;77(1):162-84.

[20] Huang JC, Shieh JP, Tang CS, et al. Low-dose dexamethasone effectively prevents postoperative nausea and vomiting after ambulatory laparoscopic surgery. Can J Anaesth 2001;48(10):973-7.

[21] Karanicolas PJ, Smith SE, Kanbur B, et al. The impact of prophylactic dexamethasone on nausea and vomiting after laparoscopic cholecystectomy: a systematic review and meta-analysis. Ann Surg 2008;248(5):751-62.

[22] Nesek-Adam V, Grizelj-Stojcic E, Rasic Z, et al. Comparison of dexamethasone, metoclopramide, and their combination in the prevention of postoperative nausea and vomiting after laparoscopic cholecystectomy. Surg Endosc 2007;21(4):607-12.

[23] Wang JJ, Ho ST, Liu YH, et al. Dexamethasone reduces nausea and vomiting after laparoscopic cholecystectomy. Br J Anaesth 1999;83(5):772-5.

[24] Fukami Y, Terasaki M, Okamoto Y, et al. Efficacy of preoperative dexamethasone in patients with laparoscopic cholecystectomy: a prospective randomized double-blind study. J Hepatobiliary Pancreat Surg 2009;16(3):367-71.
[25] Bianchin A, De Luca A, Caminiti A. Postoperative vomiting reduction after laparoscopic cholecystectomy with single dose of dexamethasone. Minerva Anestesiol 2007;73(6):343-6.

[26] Wang JJ, Ho ST, Liu HS, et al. Prophylactic antiemetic effect of dexamethasone in women undergoing ambulatory laparoscopic surgery. $\mathrm{Br} \mathrm{J}$ Anaesth 2000;84(4):459-62.

[27] Henzi I, Walder B, Tramer MR. Dexamethasone for the prevention of postoperative nausea and vomiting: a quantitative systematic review. Anesth Analg 2000;90(1):186-94.

[28] Fujii Y, Tanaka H, Toyooka H. Granisetrondexamethasone combination reduces postoperative nausea and vomiting. Can J Anaesth 1995;42(5 Pt 1):387-90.

[29] Wang JJ, Ho ST, Tzeng JI, et al. The effect of timing of dexamethasone administration on its efficacy as a prophylactic antiemetic for postoperative nausea and vomiting. Anesth Analg 2000;91(1):136-9.

[30] Jee YS, Yoon HJ, Jang CH. Prophylactic antiemetic effects in gynecologic patients receiving fentanyl IVpatient controlled analgesia: comparison of combined treatment with ondansetron and dexamethasone with metoclopramide and dexamethasone. Korean J Anesthesiol 2010;59(5):335-9.

[31] Gan TJ, Meyer TA, Apfel CC, et al. Society for Ambulatory Anesthesia guidelines for the management of postoperative nausea and vomiting. Anesth Analg 2007;105(6):1615-28.

[32] Coloma M, Duffy LL, White PF, et al. Dexamethasone facilitates discharge after outpatient anorectal surgery. Anesth Analg 2001;92(1):85-8.

[33] Liu K, Hsu CC, Chia YY. The effective dose of dexamethasone for antiemesis after major gynecological surgery. Anesth Analg 1999;89(5):1316-8.

[34] De Oliveira GS, Almeida MD, Benzon HT, et al. Perioperative single dose systemic dexamethasone for postoperative pain: a meta-analysis of randomized controlled trials. Anesthesiology 2011;115(3):575-88.

[35] Holte $K$, Kehlet $H$. Perioperative single-dose glucocorticoid administration: pathophysiologic effects and clinical implications. J Am Coll Surg 2002;195(5):694-712. 